\title{
A Study on Difficulty Applicability and Teaching Forms of Management Case Teaching in Undergraduates
}

\author{
Liqin Chen \\ School of Humanities and Economic Management, China University of Geosciences \\ Beijing 100083, China \\ E-mail: chenlq@cugb.edu.cn \\ Henghai Zhao \\ School of Humanities and Economic Management, China University of Geosciences \\ Beijing 100083, China \\ Cong Ding \\ School of Humanities and Economic Management, China University of Geosciences \\ Beijing 100083, China
}

\begin{abstract}
Management, a basic course, calls for improvement in its teaching methods. Case teaching is being extensively employed since real management practice is simulated in it.

In spite of some existing researches on "how to divide cases in difficulty" and "the objectives of case teaching", only a few of them are on the relations between the difficulty of case teaching and the reception of teaching objects. We are lacking in studies on class scale, class time allocation and the number of participants in this field, not to mention those on undergraduates. Based on the three-dimensional cubic model of case difficulty, this paper conducts an empirical research on undergraduates in questionnaire surveys and semi-structured interviews. It is shown in this research that complex cases with multi perspectives involving low difficulty in information collection and analysis are more suitable for students at this stage. In addition, the time allocated for case teaching should be nearly $50 \%$ and major and minor cases can be mixed in each chapter. It is also better to have case teaching with a two-class scale.
\end{abstract}

Keywords: Management, Case teaching, Undergraduate, Difficulty applicability

To manage means to achieve goals by comprehensively exploiting a variety of resources in an organization, hence indispensable for any organization. Based on economics, behavioral science and mathematics, management covers a wide range including branches of basic theories, branches of techniques and practical branches. In addition, the management of all organizations, including global, national, regional corporate, nor-profit and family ones, is divided into three levels (basic management, functional management and strategic management). Due to its fundamental role, management needs to be improved in its teaching contents and methods. Therefore, case teaching seems particularly effective to equip students with both basic management theories and practical ability and quality in solving problems.

Currently, case teaching is widely adopted in China's management teaching. However, due to insufficient researches on case difficulty and forms of students' participation, students' participation and enthusiasm for class are suffering. The present researches are mainly focused on how to organize class (Chen liqin \& Zhao henghai, 2006). For example, it is widely accepted by scholars that a complete case is made up of six parts including introduction, background, specific field, specific items for decision, choices and conclusion. In spite of some existing researches on "how to divide cases in difficulty" and "the objectives of case teaching", only a few of them are on the relations between the difficulty of case teaching and the reception of teaching objects (Wang, Shujuan \& Wang, Xiaotian, 2008). According to some scholars, this method is accepted by postgraduates (Jimmy Chang, 2005) but few importance has been put on the researches on case quantity, class time and the number of participants, not to mention those on undergraduates. Therefore, it is particularly important to offer a model reflecting students' degree of acceptance of case difficulty, class scale as well as class time for teachers in undergraduate management teaching.

Based on some theories including the three-dimensional cubic model of case difficulty and applying them to some aspects such as class time, case quantity and class scale, this paper conducts an empirical research on undergraduates in questionnaire surveys and semi-structured interviews. 


\section{Literature Review}

\subsection{Business Administration Cases and Its Case Teaching}

Cases are generally some issues recorded during business operation as well as some relevant facts, advice and suggestions for executives to rely on to make their decisions, which provide some practical circumstances on which students are expected to analyze, discuss and make their decisions. According to some scholars, a case, the description of certain factual situations in an organization, often involves a decision, a challenge, an opportunity, a problem or an issue for one or some members in it. Merseth (1996) claims that cases are narrative documents about real teaching situations and events; they reveal the background and something about the characters of a story from different perspectives; cases for discussion must have enough details and necessary information for users to interpret and analyze.

It is generally assumed that cases are based on some real events and are authorized to be publicized by some enterprises instead of fabricating ones. Stake (2000) defines case study as the course to interpret behavior (in a single event) under specific circumstances or in specific conditions. According to Yin $(1981,1989)$, case study for teaching does not necessarily give a complete or exact description of real events because it mainly prepares a framework for students' discussion and argument. Therefore, standards for a teaching-oriented case are quite different from those for a research-oriented one. However, it is the very purpose of case teaching to achieve better teaching effect with real cases and contents since students' disbelief in the authenticity of cases will influence the given purposes as well as consequent teaching effects. What is more important is it is difficult to guarantee students' experience in solving similar problems with such inauthentic problems.

Case teaching, forming cases for students to think, analyze and make decisions by typifying some real situations, helps to improve students' abilities in analyzing and solving problems by encouraging them to have profound analysis on enterprises' operation and find out the source of their problems and figure out solutions to them. Such participation-oriented method helps to deepen former theoretical teaching, to enhance students' understanding of knowledge, to exert their thinking capacity, to cultivate students' creativity and to improve their practical management ability, hence being widely adopted by many business schools all over the world.

Ever since it was introduced to corporate management teaching in Harvard Business School in 1908, both teachers and students benefit a lot from case teaching. With this method, American teaching institutes have cultivated a lot of first-class managers to create their prosperous economy. According to statistics, MBA students in some world-famous universities have to finish 7-9 cases every day, which sets solid foundation for their later capacity in dealing with complicated business.

Even if students have grasped modern management ideas, the basic methods of management organization and patterns during their study, these are useless because they have not gone through any practice. As a result, practice seems particularly significant to test students' grasp of basic knowledge, to detect and make up their shortcomings, to improve their flexible use of knowledge and therefore to prepare them for future management innovation. In addition, since these selected cases involve some relatively complete events (especially comprehensive ones) in business operation, great convenience is provided for students to have overall management practice and have their innovative abilities cultivated. In order to analyze cases or answer questions in them, students have to go through every stage in analyzing and solving problems with every possible method, hence cultivating their own abilities in collecting, analyzing and employing information, cultivating their abilities in assessing the solutions in cases, cultivating their abilities in proposing creative solutions based on their reasons, cultivating their persuasive abilities and their abilities in writing analysis reports as well as composing cases themselves (mainly students for Master's Degree or MBA). All these reflect their innovative management capacity.

\subsection{Objectives of Case Teaching and the Three-Dimensional Cubic Model of Case Difficulty}

With the conduction of case teaching, researches on it are booming, most of which are about its class organization and its teaching objectives.

Scholars including Romm and Mahler (1991)and Osigweh (1989) have conducted quite a lot of researches on the objectives of case teaching, forming different opinions about different issues, ranging from the acquisition of professional knowledge to the improvement of communicative abilities, from the acquisition of specialized knowledge to the recognition of and solution to problems from a strategic perspective.

Different cases reflect different characteristics, forming different types of cases for different teaching purposes. Reynolds (1978) divides case characteristics into three dimensions including data, analysis method and value. The data dimension can be regarded as a universal continuum, whose complexity degree depends on teaching purposes. The same is true for the analysis method dimension, ranging from cases for getting familiar with analysis methods to cases with few or no signal about analysis methods. The value dimension continuum has some single value systems such as efficiency, profit-earning capacity and long-term profit maximization at one end and some complex value systems such 
as those of profit, environmental protection, morality and social responsibility at the other. All these are related to analysis methods and decision-making standards.

Mauffette-leenders et al (2001) claim that cases differ in dimensions of formulation, analysis and theory. According to his model, the difficulty of a case for students can be assessed and analyzed at three dimensions, each of which can be divided into three levels (1 means "easy", 2 means "with intermediate difficulty" and 3 means "very difficult"). Accordingly, as is shown in Figure 1, a cubic model is formed, which is the three-dimensional cubic model of case difficulty.

Among the three axes in the three-dimensional cubic model of case difficulty, $\mathrm{x}$ means the analysis dimension: 1 stands for cases giving not only the description of situations but problems and solutions ; 2 stands for cases giving situations and problems but having not solutions; 3 stands for those only giving situations, leaving problems or solutions untouched.

y means the concept and method dimension: 1 stands for cases in which simple, basic or exploratory methods are employed to solve problems with concepts or branches belonging to the same branch or field; 2 stands for cases at least partly employing complex concepts or methods which are from different branches or fields; 3 stands for cases with profound and complicated concepts and high comprehensive degree in which a variety of branches or fields are mixed together.

$\mathrm{z}$ means the information dimension: 1 stands for cases providing a little but complete and concentrated information which is delivered in a direct, systematic and clear way; 2 stands for cases with more information which is given in a dispersed and disordered way, some of which has to be obtained through calculation and even some decisions are made based on assumption due to the lack of some important information; 3 stands for cases with complicated, disordered and sometimes indirect, irrelevant or even wrong information and without some key information.

27 different difficulty combinations are included in such a cube, in which the combination of "111" is the easiest one and " 333 " is the most difficult one at all three dimensions.

The data dimension defined by Reynolds is the same at the formulation dimension given by Mauffette-Leenders et al. Although it provides a clearer division at the analysis dimension, the latter covers a narrower range at its theory dimension than the value dimension of the former because cases in a specific branch of study only involve one-fold value system while almost all real decisions have to be made based on comprehensive consideration.

\section{A Study on Difficulty Applicability and Teaching Forms of Management Case Teaching in Undergraduates}

Questionnaires are designed according to the three-dimensional cubic model of case difficulty. In addition, taking the characteristics and demands of undergraduates' learning of management into consideration, we add another three-dimensional frame into our study, which includes the time allocated to case teaching, the number of cases and the number of participants. From the perspective of students' cognition of case teaching, we conducted a questionnaire survey with the method of random sampling on the undergraduates learning management in a Beijing university, in which 100 questionnaires were distributed, 92 were returned (the recorery rate of 92\%) and 87 were valid (the validity rate of $87 \%)$.

\subsection{Difficulty Applicability of Management Case Teaching in Undergraduates}

In order to make our study more representative, we pick out the item chosen by the greatest number of students, as is shown in Table 1.

It is shown that 47 undergraduates, more than $50 \%$ of all, choose the combination of " 121 ", which means that most of them hope to have detailed information and solutions in given cases instead of exploring the answer by themselves due to the influences of China's traditional education pattern. In addition, in order to be trained in their ability in comprehensively employing different management functions, more students tend to chose at least a part of complex concepts or methods involved in cases. Because undergraduates are lacking in practical management experience, understanding capacity of management theories, reading and understanding capacity of cases as well as ability in analyzing cases with the theories they have learnt, it is quite all right that most of them choose this combination. Therefore, it is assumed that the teaching objectives based on this difficulty combination will satisfy these investigated undergraduates' demands.

\subsection{The Three-Dimensional Combination of the Number of Cases, Time and Scale}

According to the principle of the cubic model of case difficulty, we set up another cubic model with the number of cases, time and the number of participants. $x$ means the number of cases, in which 1 stands for the possibly greatest number of cases, 2 stands for one major case and several minor cases in each chapter and 3 means one major case in each chapter. $\mathrm{y}$ is the time allocated to case teaching, in which 1 is almost $100 \%, 2$ is about $50 \%$ and 3 means around $30 \%$. $\mathrm{z}$ is the number of participants, in which 1 means a single class, 2 means two classes together and 3 means over two classes. The result is shown in Table 2. 
It is revealed that 50 students, $57.47 \%$ of all, choose the " 222 " combination, reflecting a greater intensity than that in the survey on difficulty combination. More students tend to choose the pattern in which major and minor cases can be combined in each chapter and about half class time is arranged for case teaching with two classes learning the course together. It is obvious that they have deep interest in case teaching with the hope to be trained in their ability of solving real cases as well as learning theories along with other students.

\subsection{Empirical Study in Case Selection and Class Organization}

It is shown in our investigation on case selection that students tend to be interested in some hot cases in their discussion and teaching course in order to have their knowledge and the real cases combined. The relevant statistics are shown in Figure 2.

It is also shown that a majority of undergraduates hope to participate in teams in case selection in order to discuss and study those issues appealing to them at class. The statistics are given in Figure 3 and Figure 4.

\section{Conclusions}

The following conclusions can be reached based on the above research:

In undergraduates' management teaching, complex cases with multi perspectives and lower difficulty in information collection and analysis are more suitable for students at this stage. Some cases giving the problems and solutions as well as the situations are quite easy for students while some with a larger store of information as well as at least one part of complex concepts and methods coming from different branches of study or fields have to be solved with a group's joint efforts. Certain objectives, such as cultivating students comprehensive abilities and teamwork abilities as well as their abilities in assessment, decision making and taking actions and their learning, understanding and employment of concepts, can be achieved during the course. Such case difficulty is fit for these undergraduates.

In addition, more students tend to choose the pattern in which major and minor cases can be combined in each chapter and about half class time is arranged for case teaching with two classes learning the course together. This pattern will enable students to quickly learn about the application of management knowledge to practical cases in a more rich and interesting way. Besides, students' teamwork spirit can be enhanced during their discussions and efforts to solve cases.

In case teaching, it is up to the teacher to select cases while students should also participate in it in order to have more effective teaching and learning course. Meanwhile, a reasonable use of hot cases and group discussions will enhance the effect of case teaching. It is quite interest that these students show their lack of interest in current affairs and some complicated major cases and therefore the selection of cases for their class in our semi-structured interviews in spite of their great passion for hot cases. In order to solve this problem, on one hand, teachers should have more communication with students; on the other hand, teachers may guide them by intensifying class organization and management, which is also a new perspective for further study in this filed.

\section{Note}

One of accomplishments of elaborate course constructon of management in China University of Geosciences (in the charge of Henghai Zhao).

\section{References}

Chang, Jimmy. et al. (2005). Students' View on the Use of Case Method in China. Developments in Business Simulation and Experiential Learning, Vol. 32, Pp. 86-90.

Chen, Liqin, \& Zhao, Henghai. (2006). Methods and Implementation of Management Case Teaching. Journal of Capital Unviesity of Economicis and Business. January

Gragg, C. I. (1940/1982). Because Wisdom Can't Be Told. Harvard Alumni Bulletin. October 19. 1040. Reissued by Harvard Business School, Report 9-451-005, Rev. November 30, 1982. McGraw-Hill Companies, 2001.

Mauffette-leenders, Louise A, James A. Erskine \& Michiel R. leenders. (2001). Learning with Cases (2nd ed.), Richard Ivey School of Business, Ivey Publising.

Osigweh, C. A.B. (1989). Casing the Case Approach in Management Development. Journal of Management Development, Vol. 8, No.2, pp. 41-57.

Reynolds, J.I. (1978). There is Method in Cases, Academy of Management Review, 3(1): pp. 129-133.

Romm, T. and Mahler, S. (1991). The Case Study Challenge: A New Approach to an Old Method. Management.

Stake, R.E. (2000). Case studies. In N.K.Denzin \& Y.S.Lincoln (Eds.). Handbook of Qualitative Research (2nd ed.): pp 435-454 Thousand Oaks. CA: Sage Publications.

Wang, Shujuan, \& Wang, Xiaotian. (2008). Study on Difficulty Applicability of Cases Employed in Management Teaching. Journal of Management Case Studies, 1 (2), pp. 84-88. 
Yin, R. (1981). The Case Study Crisis:Some Answers. Administrative Science Quarterly, 26, pp. 58-65.

Yin, Robert K. (1989). Case Study Research: Design and Methods (Rev.ed). Beverly Hill. Calif.

Yu, Jing. (2004). Case Studies and Methods. Economic Management: New Management, 20.

Table 1. Difficulty combination of cases chosen by undergraduates

\begin{tabular}{|c|c|c|c|}
\hline Object & $\begin{array}{c}\text { Chosen difficulty } \\
\text { combination }\end{array}$ & $\begin{array}{c}\text { Number of students } \\
\text { choosing it }\end{array}$ & Percentage \\
\hline Undergraduates & 121 & 47 & $54.02 \%$ \\
\hline
\end{tabular}

Table 2. The combination of the number of cases, time and scale chosen by undergraduates

\begin{tabular}{|c|c|c|c|}
\hline Object & Chosen combination & $\begin{array}{c}\text { Number of students } \\
\text { choosing it }\end{array}$ & Percentage \\
\hline Undergraduates & 222 & 50 & $57.47 \%$ \\
\hline
\end{tabular}

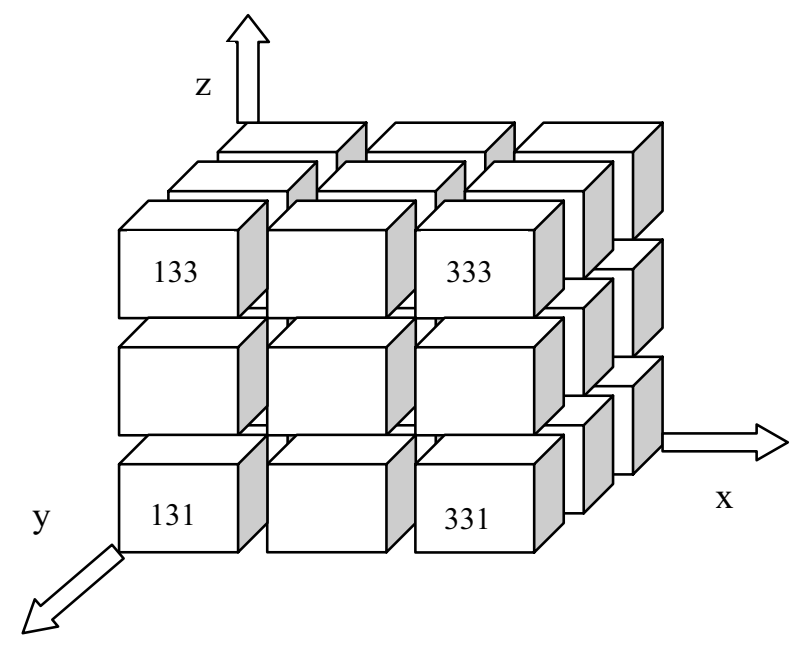

Figure 1. Three-Dimensional Cubic Model of Case Difficulty

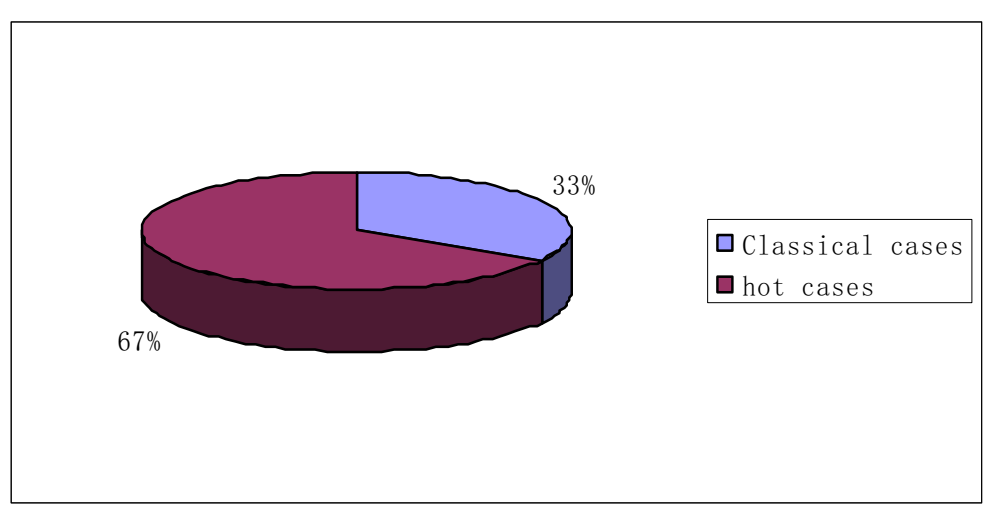

Figure 2. Undergraduates' Selection of Management Cases 


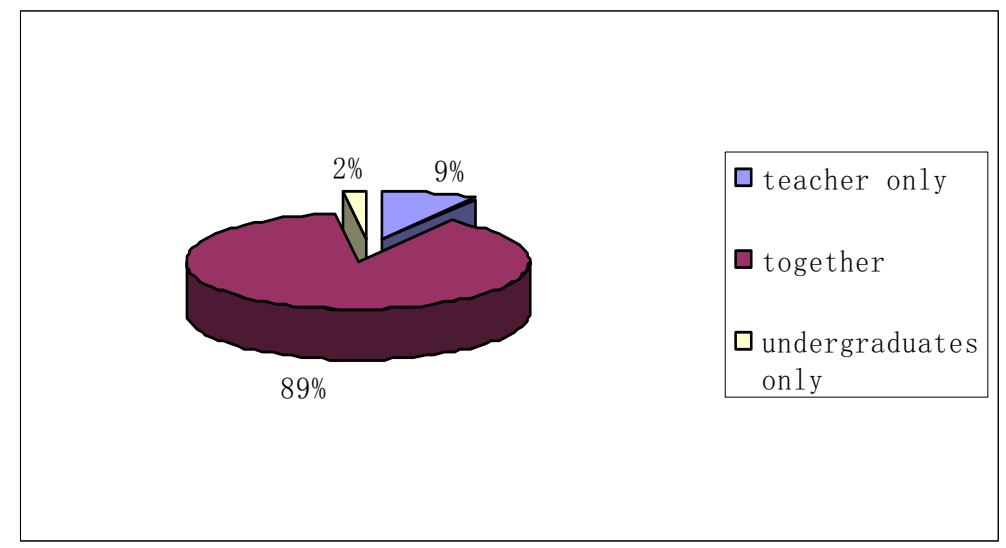

Figure 3. the Method of case selection

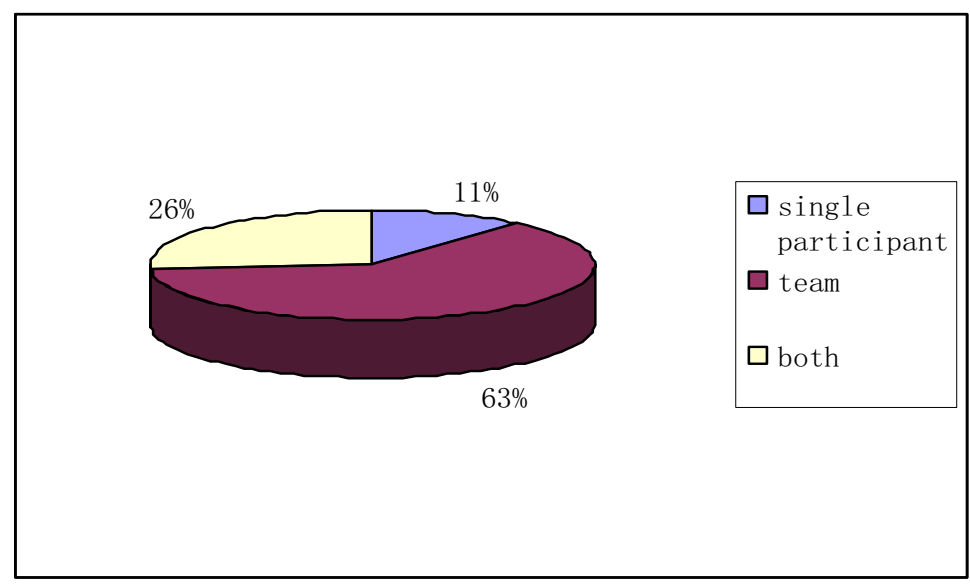

Figure 4. Class organization of management cases 